\title{
Workplace bullying and workplace violence as risk factors for cardiovascular disease : a multi-cohort study
}

\section{Xu, Tianwei}

2019-04-07

Xu , T, Magnusson Hanson , L L , Lange , T, Starkopf , L , Westerlund , H, Madsen , I E H , Rugulies , R , Pentti , J , Stenholm , S, Vahtera, J , Hansen, A M , Virtanen, M , Kivimäki , M \& Rod , N H 2019 , ' Workplace bullying and workplace violence as risk factors for cardiovascular disease : a multi-cohort study ' , European Heart Journal , vol. 40 , no. 14 , pp. 1124-+ . https://doi.org/10.1093/eurheartj/ehy683

http://hdl.handle.net/10138/301712

https://doi.org/10.1093/eurheartj/ehy683

publishedVersion

Downloaded from Helda, University of Helsinki institutional repository.

This is an electronic reprint of the original article.

This reprint may differ from the original in pagination and typographic detail.

Please cite the original version. 


\title{
Workplace bullying and workplace violence as risk factors for cardiovascular disease: a multi-cohort study
}

\author{
Tianwei $\mathrm{Xu}^{1,2,3 *}$, Linda L. Magnusson Hanson ${ }^{2}$, Theis Lange ${ }^{4,5}$, Liis Starkopf ${ }^{4}$, \\ Hugo Westerlund ${ }^{2}$, Ida E.H. Madsen ${ }^{3}$, Reiner Rugulies ${ }^{1,3,6}$, Jaana Pentti ${ }^{7}$, \\ Sari Stenholm ${ }^{7}$, Jussi Vahtera ${ }^{7}$, Åse M. Hansen ${ }^{3,8}$, Marianna Virtanen ${ }^{2,9,10}$, \\ Mika Kivimäki ${ }^{9,11,12}$, and Naja H. Rod ${ }^{1,2}$
}

\begin{abstract}
${ }^{1}$ Section of Epidemiology, Department of Public Health, University of Copenhagen, Gothersgade 160, DK-1123 Copenhagen, Denmark; ${ }^{2}$ Division for Epidemiology, Stress Research Institute, Stockholm University, SE-10691, Stockholm, Sweden; ${ }^{3}$ National Research Centre for the Working Environment, Lersø Parkallé 105, DK-2100 Copenhagen, Denmark; ${ }^{4}$ Section of Biostatistics, Department of Public Health, University of Copenhagen, Øster Farimagsgade 2A, DK-1353 Copenhagen, Denmark; ${ }^{5}$ Centre for Statistical Science, Peking University, No. 5 Yiheyuan Road, Beijing CN-100871, China; ${ }^{6}$ Department of Psychology, University of Copenhagen, Øster Farimagsgade 2A, DK-1353 Copenhagen, Denmark; ${ }^{7}$ Department of Public Health, University of Turku and Turku University Hospital, Fl-20014 Turku, Finland; ${ }^{8}$ Section of Social Medicine, Department of Public Health, University of Copenhagen, Gothersgade 160, DK-1123 Copenhagen, Denmark; ${ }^{9}$ Finnish Institute of Occupational Health, Topeliuksenkatu 41 b, FI-00250 Helsinki, Finland; ${ }^{10}$ Department of Public Health and Caring Sciences, University of Uppsala, Husargatan 3, 75237 Uppsala, Sweden; ${ }^{11}$ Department of Epidemiology and Public Health, University College London, 1-19 Torrington Place, London, WC1E 7HB, UK; and ${ }^{12}$ Clinicum, Faculty of Medicine, PO Box 63, FI-00014 University of Helsinki, Helsinki, Finland
\end{abstract}

Received 7 April 2018; revised 15 July 2018; editorial decision 28 September 2018; accepted 8 October 2018; online publish-ahead-of-print 19 November 2018

See page 1135 for the editorial comment on this article (doi: 10.1093/eurheartj/ehy728)

Aims To assess the associations between bullying and violence at work and cardiovascular disease (CVD).

Methods Participants were 79201 working men and women, aged 18-65years and free of CVD and were sourced from and results three cohort studies from Sweden and Denmark. Exposure to workplace bullying and violence was measured at baseline using self-reports. Participants were linked to nationwide health and death registers to ascertain incident CVD, including coronary heart disease and cerebrovascular disease. Study-specific results were estimated by marginal structural Cox regression and were combined using fixed-effect meta-analysis. Nine percent reported being bullied at work and 13\% recorded exposure to workplace violence during the past year. We recorded 3229 incident CVD cases with a mean follow-up of 12.4 years (765 in the first 4 years). After adjustment for age, sex, country of birth, marital status, and educational level, being bullied at work vs. not was associated with a hazard ratio (HR) of 1.59 [95\% confidence interval (Cl) 1.28-1.98] for CVD. Experiencing workplace violence vs. not was associated with a HR of $1.25(95 \% \mathrm{Cl} 1.12-1.40)$ for CVD. The population attributable risk was $5.0 \%$ for workplace bullying and $3.1 \%$ for workplace violence. The excess risk remained similar in analyses with different follow-up lengths, cardiovascular risk stratifications, and after additional adjustments. Dose-response relations were observed for both workplace bullying and violence $\left(P_{\text {trend }}<0.001\right)$. There was only negligible heterogeneity in study-specific estimates.

$\begin{array}{ll}\text { Conclusion } & \text { Bullying and violence are common at workplaces and those exposed to these stressors are at higher risk of } \\ \text { CVD. }\end{array}$

Keywords Workplace • Bullying • Violence • Cardiovascular disease • Psychosocial stress • Occupational health

* Corresponding author. Tel: +45 3533 6295, Email: tixu@sund.ku.dk

Published on behalf of the European Society of Cardiology. All rights reserved. @ The Author(s) 2018. For permissions, please email: journals.permissions@oup.com. 


\section{Introduction}

Adverse psychosocial working conditions, including job strain, effortreward imbalance, and long working hours are associated with a higher risk of cardiovascular disease (CVD). ${ }^{1}$ Other potentially severe workplace stressors such as bullying and violence are associated with a moderately higher risk of type 2 diabetes, ${ }^{2}$ but their status as risk factors for CVD remains unclear.

Workplace bullying and violence constitute different social stressors. Workplace bullying is characterized by repeated or enduring psychologically aggressive behaviours at work, ${ }^{3}$ whereas workplace violence is known as the intentional use of physical force or threats of such actions at work (definitions are provided in Supplementary material online, Text S1). ${ }^{4}$ As social stressors, both workplace bullying and violence may contribute to lowered self-esteem and loss of coping resources. ${ }^{3}$ They may also elicit a range of coping-oriented behavioural changes, such as over-eating and excessive alcohol consumption, ${ }^{5-7}$ and induce a variety of negative emotions. ${ }^{8-10}$ For example, bullied individuals are three times more likely to report a depressed mood, whereas increased feelings of anger have been noted among people exposed to workplace violence. ${ }^{8-10}$ In addition, both bullying and violence can lead to anxiety. ${ }^{9,10}$ It has been hypothesized that these coping-oriented behaviours and negative emotions increase CVD risk, ${ }^{11-13}$ along with various stress-related physiological reactions, including elevated blood pressure, increased heart rate, and systemic inflammation level. ${ }^{1}$ They can also result in reduced insulin sensitivity, increased platelet aggregation, and hypercoagulability, endothelial dysfunction, and arrhythmias. ${ }^{1}$

Only a few studies have examined the risk of CVD in employees exposed to bullying at work and the results are conflicting. ${ }^{14-17}$ Bullying was associated with a higher risk of incident CVD in 601 male and 4831 female Finnish hospital employees followed for 2 years with self-reported outcome, and in a case-control study of 7374 CVD cases and 7374 CVD-free controls extracted from primary care documentation from Germany. ${ }^{15,17}$ However, in a cross-sectional study in the USA based on 17524 adults, an association was noticed with selfreported angina pectoris but not with ischaemic heart disease or stroke. ${ }^{16}$ These conflicting results may be due to a low number of outcome events, ${ }^{15,16}$ imprecise measurements of CVD endpoints, ${ }^{15-17}$ and uncontrolled or imprecisely measured key confounders, such as employment status and educational level, ${ }^{17}$ making the association between workplace bullying and CVD unclear. Regarding violence, most research has focused on intimate partner violence or general violence, rather than violence occurring at the workplace specifically. ${ }^{18}$ Although both environmental threats to security (e.g. national monthly homicide counts) and incidence of physical assault have shown to be associated with higher rates of CVD death, ${ }^{19,20}$ the association between workplace violence and incident CVD is still inconclusive.

To address these limitations, we pooled individual-level data from three large longitudinal studies including a total of 79201 men and women to examine the prospective associations between workplace bullying and workplace violence with incident CVD.

\section{Methods}

\section{Study population}

Four independent cohorts were utilized in this study, taken from the following three population-based studies: the Swedish Work Environment
Survey (SWES) (divided into two cohorts with baseline years 1995/1997/ 1999/2001 and 2007/2009/2011, source population: participants of Swedish Labour Force Survey; response proportion: 79\%), ${ }^{21}$ the Swedish Longitudinal Occupational Survey of Health (SLOSH) (baseline: year 2006/2008, source population: participants of SWES; response proportion: 65\%), ${ }^{22}$ and the Danish Work Environment Cohort Study (DWECS) (baseline: year 2005, source population: random sample from Danish population register; response proportion: 63\%) ${ }^{23}$ (Figure 1). In cohorts with multiple baseline years, we only kept the first participation record. Until 2012, SLOSH collected follow-up information on a biannual basis, and 38\% of all respondents of the SLOSH2006/2008 respondents answered all follow-up surveys. Detailed descriptions of each cohort can be found in the Supplementary material online, Text S2.

Using the personal identification number assigned to all residents in Sweden and Denmark, participants were linked to national registries in each country. We included employees aged 18-65 years, with no prior CVD and with information available on workplace bullying or violence, totalling a sample of 79201 participants (Figure 1).

Ethical approval was obtained from the Regional Ethical Review Board in Stockholm for SWES and SLOSH. ${ }^{22}$ DWECS was approved by the Danish Data Protection Agency (registration number: 200754-0059). ${ }^{24}$

\section{Assessment of baseline workplace bullying and violence}

Workplace bullying was assessed via a self-administered questionnaire measuring whether the participant had been bullied within the 12 months preceding the baseline. Exposure to violence at work was defined as being exposed to violent actions or threats of violence at work within 12 months prior to the baseline. Please see Supplementary material online, Table S1 for details. SWES and SLOSH also included information about the frequency of exposure. We constructed a dose-response variable with the categories 'frequently exposed' (exposed more than once a week), 'occasionally exposed' (less than once a week, but at least one exposure within the past 12 months), and 'not exposed'.

\section{Ascertainment of cardiovascular disease}

Incident CVD is a composite outcome including diagnoses of the first hospitalization with coronary heart disease (CHD) or cerebrovascular disease (CD). They were identified through nationwide registries based on the International Classification of Diseases (ICD) 8, 9, and 10 codes. Main diagnoses in inpatient register (in SLOSH, SWES95-01, SWES07-11, and DWECS), outpatient register (in SLOSH, SWES07-11 and DWECS) and death registers (in SLOSH, SWES95-01, SWES07-11, and DWECS) were used. The diagnostic codes for CHD were ICD-10 I20.0, I20.1, I21125 (excluding unspecified angina), and ICD-8/9 410-414, whereas ICD10 160-169, and ICD-8/9 430-438 were used to detect CD. Definitions of specific CVD subtypes, such as myocardial infarction (MI), ischaemic stroke (IS), and haemorrhagic stroke (HS) can be found in the Supplementary material online, Text S3. Incident CVD cases were identified during the follow-up. Further information on standards and quality of CVD diagnosis in Denmark and Sweden can be found in Supplementary material online, Text S4.

\section{Covariates}

We used prior knowledge and the method of directed acyclic graph method to select covariates. ${ }^{25-27}$ In addition to age and sex, we identified country of birth, educational level, and marital status as potential confounders. This information was all register-based. Educational level was classed as ' $\leq 9$ years', '10-12 years', and ' $\geq 13$ years'. Baseline marital status was categorized as unmarried, married/cohabiting, divorced/separated, 


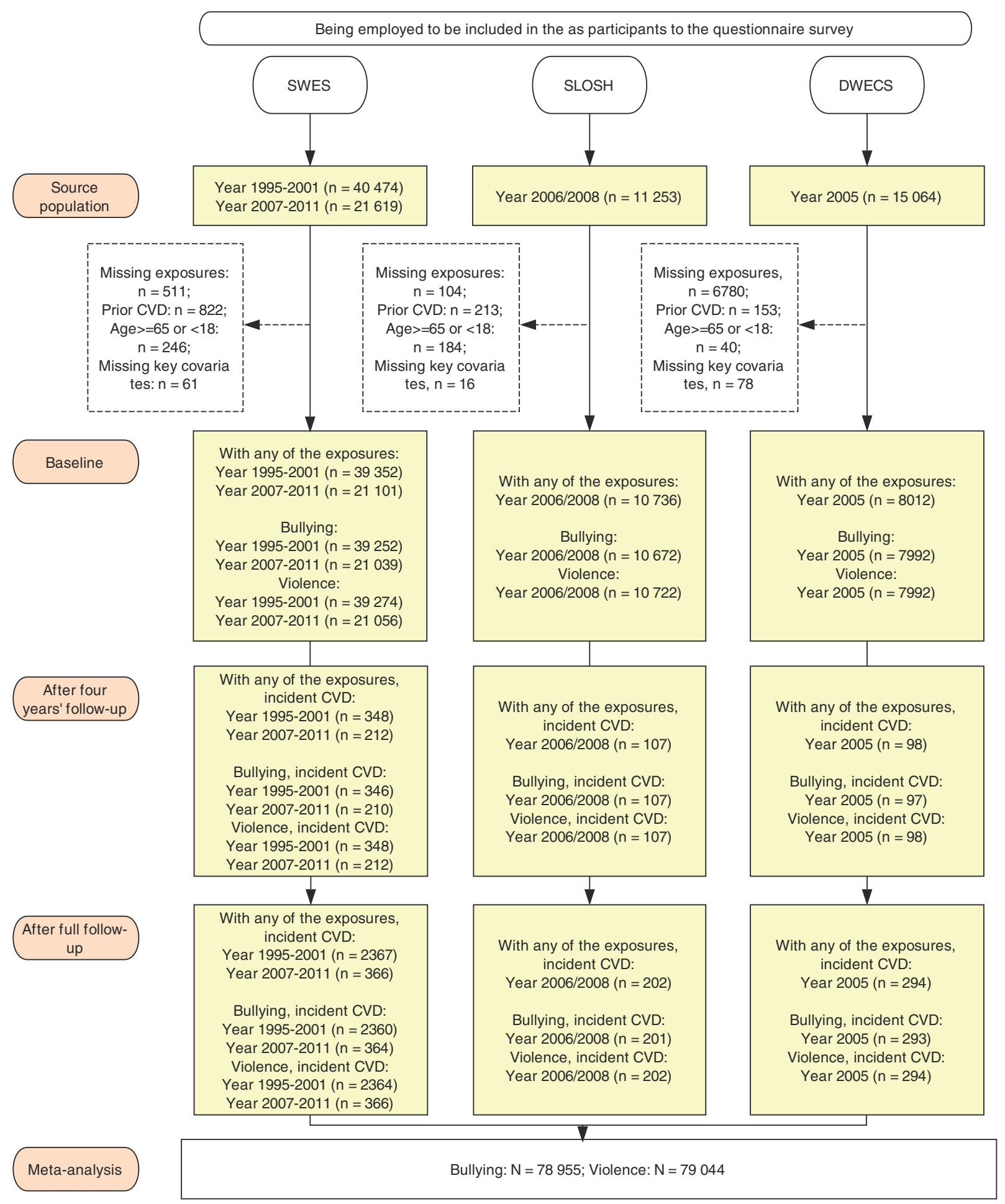

Figure I Flowchart describing study populations and analytical samples.

or widowed. Country of birth was categorized into 'Nordic countries', 'other European countries', and 'other continents'.

Body mass index (BMI), alcohol consumption, current smoking status, and mental disorders were considered both as potential confounders and mediators, and they were thus only adjusted for in the sensitivity analysis. We also considered the impact from other stressors at workplace, private life and other health conditions, which might be related to both the onset of exposure and the outcome. These included shift work occupations (e.g. health care professionals), occupational grade, having young children at home ( $<5$ years of age), family-work conflict, workplace 
role stressors, pre-existing diabetes, and other comorbidities [Charlson Comorbidity Index $(\mathrm{CCl})]$ at or prior to the baseline examination. The measurements for these variables are described in Supplementary material online, Texts S5 and S6 and Table S2.

We further hypothesized that employees in occupations with frequent client contact (and thus with a higher risk of exposure to workplace violence), are better trained to cope with violence. ${ }^{28}$ Hence, occupation could be a critical modifying factor. We defined social workers, personal and protective service workers, healthcare professionals, and teaching professionals as frequent-client-contact occupations. We used comparable ISCO-88 codes from DWECS, SWES95-01, SWES07-11, and $\mathrm{SLOSH}$, following a suggestion in Madsen et al. ${ }^{29}$

\section{Statistical analysis}

In total, eight sub-datasets (one for bullying and one for violence per cohort) with slightly varying numbers of participants were created. We applied marginal structural Cox regression to the main analyses. This approach is based on the counterfactual framework and aims to estimate the average marginal population effect, i.e. comparing a population when everyone was exposed to when everyone was not exposed. ${ }^{30}$

We calculated the individual-specific stabilized inverse probability weight. ${ }^{30}$ Different logistical models were used for calculating different weights, based on propensity score models which included the specific variables considered in each adjustment. The positivity assumption was not violated in any of the analyses, meaning that both exposure statuses were possible within each confounder strata. ${ }^{30}$ Before fitting the weighted Cox model, the proportional hazards $(\mathrm{PH})$ assumption was tested using log-log plot and interaction between time and exposure. Here, we observed an interaction between workplace bullying and follow-up length, where the hazard ratio (HR) of bullying and CVD decreased during follow-up. Thus, we restricted our analyses to the first 4 years of follow-up on workplace bullying to meet the assumption (see other motivations for choosing the 4-year follow-up limit in Supplementary material online, Text S7). For workplace violence, full follow-up length was used as there was no violation of the $\mathrm{PH}$ assumption. Later, we fitted a weighted $\mathrm{Cox} \mathrm{PH}$ model with age as the underlying time scale and obtained robust confidence intervals $(\mathrm{Cls})$ by bootstrapping 500 times.

Other main analyses included: (i) disease subtype analyses using information for MI, HS, and IS; (ii) population attributable risk (PAR) calculation, which represents the extent to which disease burden would be eliminated, had the given risk factors removed from the population and is widely used in the planning and prioritization of certain public health interventions; ${ }^{31}$ and (iii) estimation of dose-response relation. Sensitivity analysis processes are presented in Figure 2.

Due to the small number of cohorts, all cohort-specific estimates were then combined using fixed-effect meta-analysis. ${ }^{32} P^{2}$ statistic was used to test the heterogeneity of results across the cohorts. All the analyses were conducted using SAS version 9.4 (SAS Institute, Inc., Cary, NC, USA) and R package 'meta' version 4.8-4. All tests of statistical significance were two-sided and the significance level was set at 0.05 .

\section{Results}

The mean age of the participants was 43 years across the three studies and 53\% were women (see Table 1 and weighted summary in Supplementary material online, Table S3). There were 78955 participants with data on workplace bullying. The prevalence of bullying varied across the studies, ranging from $8 \%$ to $13 \%$ within the past 12 months. The perpetrators of workplace bullying (in DWECS) were mostly from inside the organization $(79 \%$ were colleagues, supervisors, or subordinates) rather than from outside (21\% were clients).

Data on workplace violence was available for 79044 participants. The prevalence ranged from $7 \%$ to $17 \%$ across the cohorts within the past 12 months. We found that social workers (prevalence $>46 \%$ ), personal and protective service workers (>29\%), healthcare professionals $(>25 \%)$, and teaching professionals $(>16 \%)$ had the highest exposure to workplace violence. The perpetrators of workplace violence (in DWECS) mainly originated from outside the organization (91\%: clients) and less often from inside (9\%: colleagues, supervisors, or subordinates).

Overall, only 10-14\% of those exposed to at least one type of exposure was suffering from the other at the same time (Cohen's Kappa <0.20). This indicates that workplace bullying and violence are two separate concepts.

\section{Workplace bullying and cardiovascular disease}

Over a mean follow-up of 3.8 years, 760 incident CVD events were recorded, including 484 incident CHD events and 301 incident CD events, with 25 participants having both CHD and CD events as their main diagnosis during follow-up.

Figure 3 shows a forest plot of the main analyses. We observed very little heterogeneity in all analyses $\left(P^{2}<0.01 \%\right)$. After adjusting for age, sex, educational level, marital status, and country of birth, workplace bullying was associated with a $59 \%$ higher risk of incident CVD (HR 1.59, 95\% Cl 1.28-1.98), with the corresponding PAR being $5.0 \%$ (95\% Cl 2.5-8.1\%). This association was presented for both incident $\mathrm{CHD}(\mathrm{HR} 1.56,95 \% \mathrm{Cl} 1.18-2.07)$ and incident $\mathrm{CD}$ (HR 1.70, 95\% Cl 1.19-2.44). We further observed an association with HS (HR 2.73, 95\% Cl 1.16-6.45) and its excess risk was much higher than for IS (HR 1.44, 95\% Cl 0.93-2.23). However, the estimate of HS was based on only 42 cases, generating a relatively wide $\mathrm{Cl}$, which overlapped with that for IS. SLOSH, SWES95-01, and SWES07-11 provided information on the frequency of workplace bullying. Of the participants who were bullied, approximately $10 \%$ were frequently bullied, whereas the remaining $90 \%$ were occasionally bullied. Dose-response relations were observed for CVD $\left(P_{\text {trend }}<\right.$ 0.001). The highest risk of CVD (HR 2.22, 95\% Cl 1.23-4.01) was found among those being frequently bullied. The same trend was presented for CHD as well as CD.

The sensitivity analyses are summarized in Figure 4. Excluding the first year of follow-up to reduce reverse causality gave congruous results for the main analysis. There was no evidence that sex, age, or smoking status influenced the results. Further variable adjustments or restriction of the population did not materially change the findings.

In SLOSH, there were 4066 participants (11 707 participantobservations) who responded to all follow-up waves (2006/20082012). With a mean follow-up of 5.9 years, 84 incident CVD cases were recorded. Among them $21 \%$ of participants were exposed to bullying at least once (10\% of total participant-observations). Treating workplace bullying and other changeable characteristics (e.g. marital status) as time-dependent variables, we found a HR of $2.10(95 \% \mathrm{Cl} 1.20-3.68)$ for the association between bullying and CVD. 


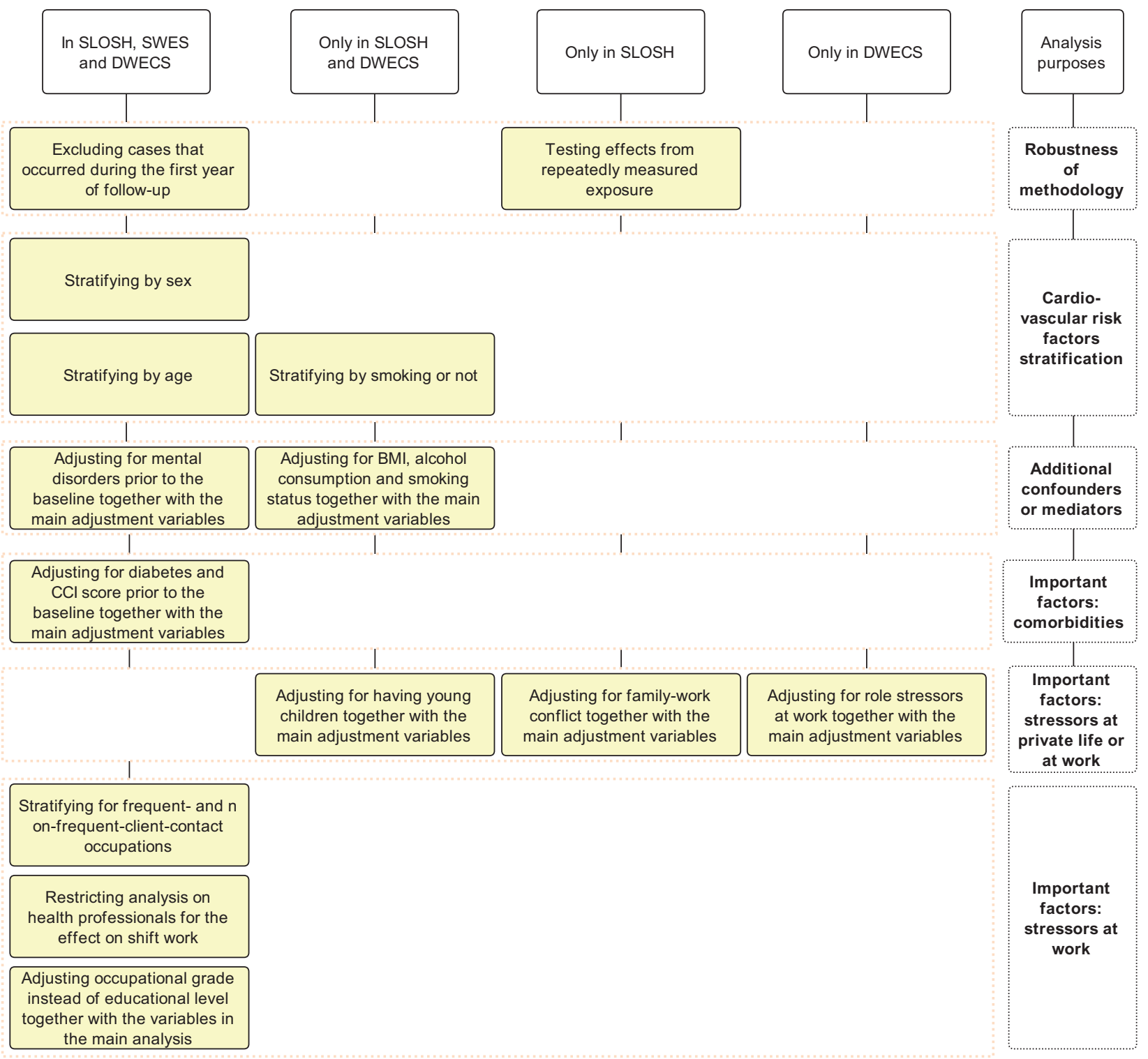

Figure 2 Overview of sensitivity analyses.

Table I Summary of studies that provided individual participant data used in the analyses for cardiovascular disease, based on largest available samples with full-follow-up length $(N=79201)$.

\begin{tabular}{|c|c|c|c|c|c|c|c|c|c|c|}
\hline Study & Country & Baseline & $\begin{array}{l}\text { Full follow-up } \\
\text { lengths (mean years) }\end{array}$ & $\begin{array}{l}\text { Women } \\
\text { (\%) }\end{array}$ & $\begin{array}{l}\text { Age (years), } \\
\text { mean (SD) }\end{array}$ & $\begin{array}{l}\text { Bullying } \\
\text { (\%) }\end{array}$ & $\begin{array}{l}\text { Violence } \\
\text { (\%) }\end{array}$ & CVD & CHD & CD \\
\hline SLOSH & Sweden & $2006 / 2008$ & 7.0 & 55 & 47 (10.6) & 13 & 17 & 26.7 & 16.2 & 10.7 \\
\hline DWECS & Denmark & 2005 & 8.9 & 51 & $43(10.4)$ & 9 & 7 & 41.2 & 21.9 & 20.4 \\
\hline SWES95-01 & Sweden & 1995/1997/1999/2001 & 17.5 & 52 & 42 (11.5) & 8 & 13 & 34.4 & 21.0 & 15.0 \\
\hline SWES07-11 & Sweden & 2007/2009/2011 & 7.1 & 53 & $44(12.0)$ & 8 & 14 & 24.4 & 14.7 & 10.1 \\
\hline Total & & 1995-2011 & 12.4 & 53 & 43.3 & 9 & 13 & 32.7 & 19.7 & 14.4 \\
\hline
\end{tabular}

Incidence rate per 10000 person-years.

$\mathrm{CD}$, cerebrovascular disease; $\mathrm{CHD}$, coronary heart disease; CVD, cardiovascular disease; SD, standard deviation. 

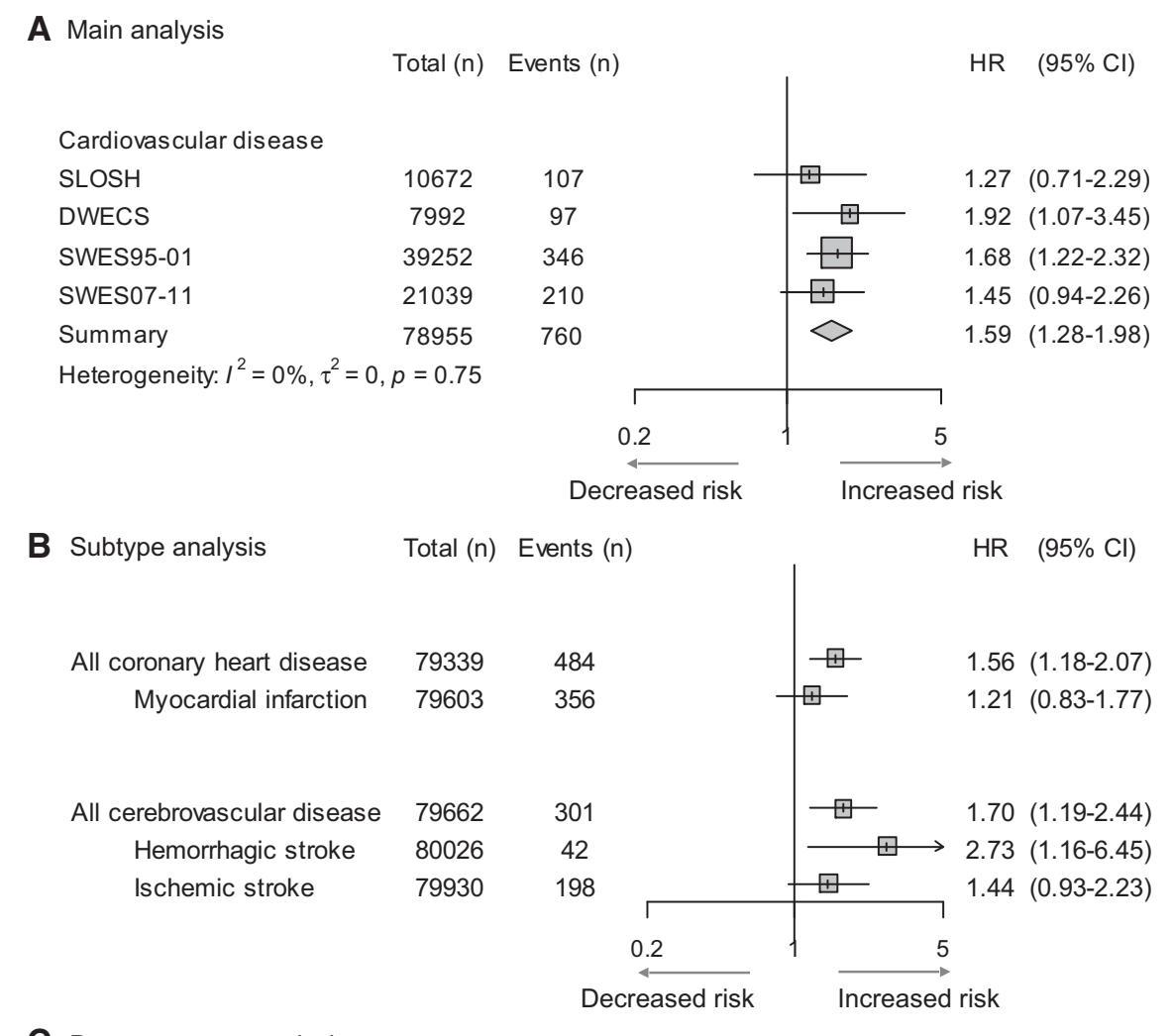

C Dose-response analysis

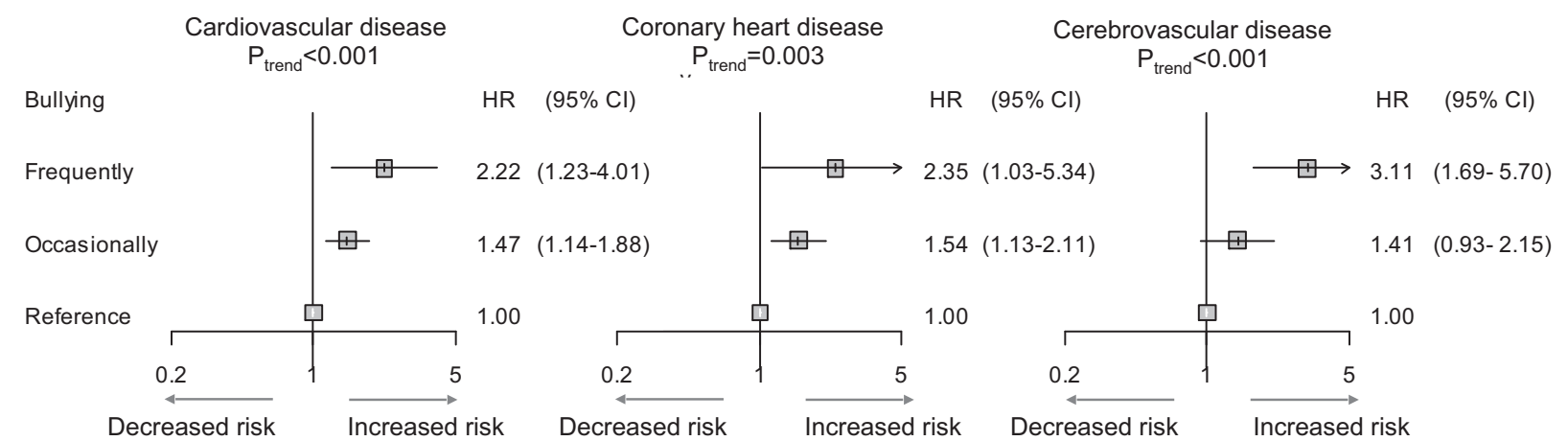

Figure 3 Fixed-effect meta-analysis of the association between workplace bullying and cardiovascular disease, after adjustment for age, sex, educational level, marital status, and country of birth, regarding $(A)$ main analysis of cardiovascular disease, $(B)$ subtype analysis of coronary heart disease and cerebrovascular disease, and $(C)$ dose-response relation analysis according to different frequencies of bullying.

\section{Workplace violence and cardiovascular disease}

During a mean follow-up of 12.4 years, 3226 incident CVD events were recorded, including 1971 incident CHD events and 1439 incident CD events. A total of 184 participants had both CHD and CD events as their main diagnosis during the follow-up.

Figure 5 shows that workplace violence was associated with a higher risk of incident CVD (HR 1.25, 95\% Cl 1.12-1.40). The corresponding PAR for workplace violence was 3.1\% (95\% Cl 1.5-4.9\%). Looking at subtypes of CVD, the association was similar for incident CHD (HR 1.21, 95\% Cl 1.03-1.42) and incident CD (HR 1.25, 95\% Cl 1.06-1.49). HS (HR 1.31, 95\% Cl 0.89-1.92) and IS (HR 1.33, 95\%
Cl 1.08-1.64) also showed similar risk estimates. There was only negligible heterogeneity across cohorts $\left(I^{2}=2 \%\right)$. We found a dose-response relation between workplace violence and risk of CVD $\left(P_{\text {trend }}<0.001\right)$. However, while the dose-response relation was presented for CD $\left(P_{\text {trend }}<0.001\right)$, it was absent for CHD $\left(P_{\text {trend }}=0.22\right)$. Frequent exposure to workplace violence was associated with $36 \%$ higher risk of incident CD (HR 1.36, 95\% Cl 0.99-1.86).

The sensitivity analyses are summarized in Figure 6. By limiting the follow-up length to the first 4 years, and excluding the first year of follow-up, the sensitivity analyses showed similar associations. No sex, age, and smoking status differences were observed, and further 
Follow-up length

Main $=$ first 4 years

From 1 year after baseline

Sex

Male

Female

Age

Yonger than 50 years

50 years or older

Current smoking status - in SLOSH and DWECS ${ }^{a}$

Not smoking

Smoking

Adjustments: Mental disorders

Age, sex, educational level, marital status, country of birth

+ Mental disorders

Adjustments: Comorbidity

+ Diabetes

$+\mathrm{CCl}$ score

Adjustments: Life-style factors - in SLOSH and DWECS ${ }^{\text {b }}$

Age, sex

Age, sex, educational level, marital status, country of birth

+ Alcohol consumption

+ Smoking

$+\mathrm{BMl}$

+ Alcohol consumption, smoking, BMl

Adjustments: Stressors at private life or workplace

+ Having young children - in SLOSH and DWECS ${ }^{\mathrm{C}}$

+ Family-work conflict - in SLOSH ${ }^{\mathrm{d}}$

+ Role stressors at work - in DWECS ${ }^{e}$

Restriction: Night shift

Only healthcare professionals

Adjustments: Occupational grade

Age, sex, occupational grade, marital status, country of birth

a. Excluding those with missing in smoking status

b. Excluding those with missing in alcohol consumption, smoking and BMI

c. Excluding those with missing information on having young children

d. Excluding those with missing information on family-work conflict

e. Excluding those with missing information on role stressors

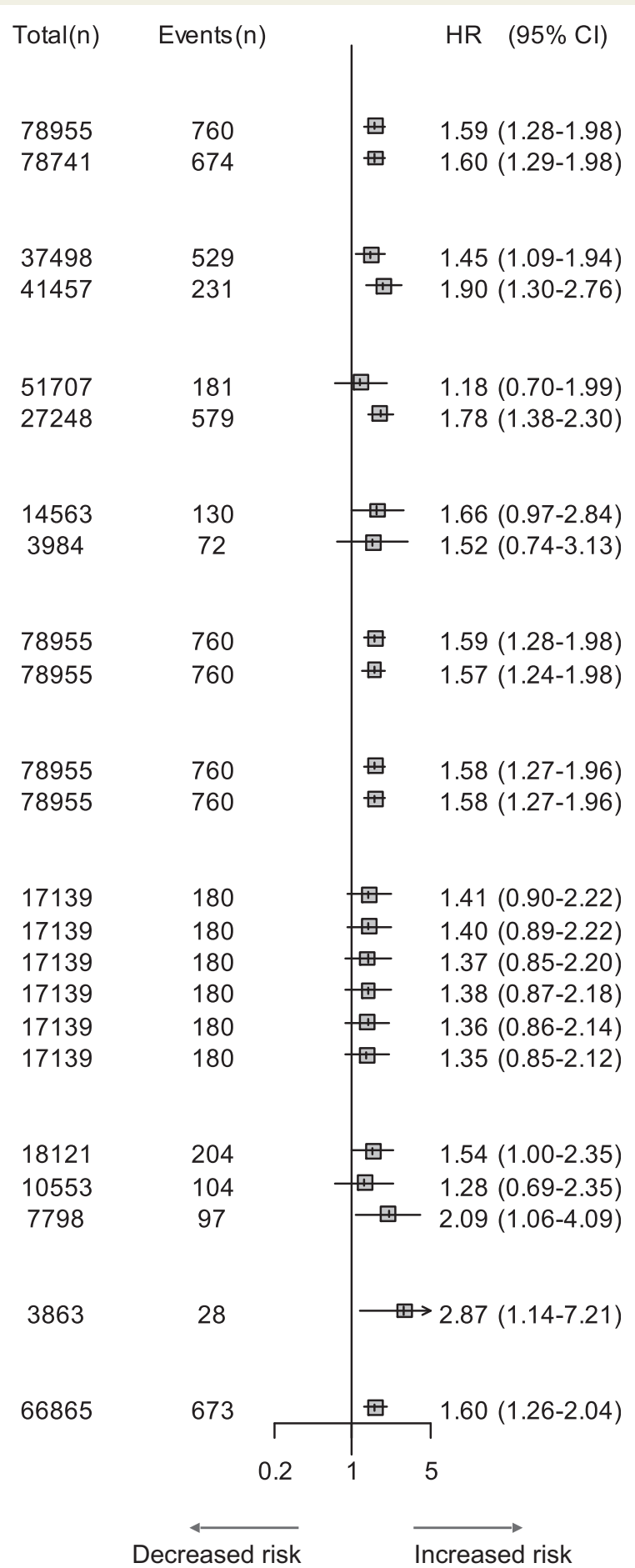

Figure 4 Sensitivity analysis of the association between workplace bullying and cardiovascular diseases, using fixed-effect meta-analyses excluding first year(s) of follow-up, stratifying for sex, and with different adjustments and restriction. adjustments did not change the effects. Moreover, we observed a stronger association between violence and CVD among people employed in non-frequent-client-contact occupations (HR 1.32, 95\% Cl 1.13-1.56) than among those whose occupations involved frequent client contact (HR 1.15, 95\% Cl 0.99-1.34), but with overlapping Cls. The latter type of occupation also shared similar results with the restricted analysis on health care professionals (night shift workers) (HR 1.06, 95\% Cl 0.68-1.63).

Among the 4751 participants of SLOSH (11 747 participantobservations) who responded to all survey waves (2006/2008-2012), the mean follow-up was 5.9 years and 86 incident CVD were recorded. Of the participants, $17 \%$ were exposed to violence at least once 


\section{A Main analysis}

Total (n) Events (n)

HR $\quad(95 \% \mathrm{Cl})$

$\begin{array}{lcc}\text { Cardiovascular disease } & & \\ \text { SLOSH } & 10722 & 202 \\ \text { DWECS } & 7992 & 294 \\ \text { SWES95-01 } & 39274 & 2364 \\ \text { SWES07-11 } & 21056 & 366 \\ \text { Summary } & 79044 & 3226 \\ \text { Heterogeneity: } I^{2}=2 \%, \tau^{2}=0.0005, p=0.38\end{array}$

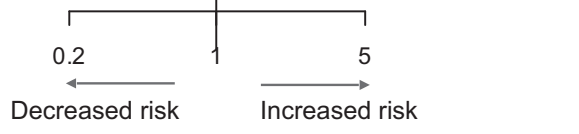

B Subtype analysis

All coronary heart disease
Myocardial infarction
All cerebrovascular disease
Hemorrhagic stroke
Ischemic stroke
Dose-response analysis
Cardiovascular disease
$\mathrm{P}_{\text {trend }}<0.001$

Total (n) Events (n)

$\mathrm{HR} \quad(95 \% \mathrm{Cl})$

$\begin{array}{ll}1.35 & (0.90-2.02) \\ 1.46 & (0.95-2.26) \\ 1.26 & (1.11-1.44) \\ 0.89 & (0.58-1.37) \\ 1.25 & (1.12-1.40)\end{array}$

Decreased risk Increased risk

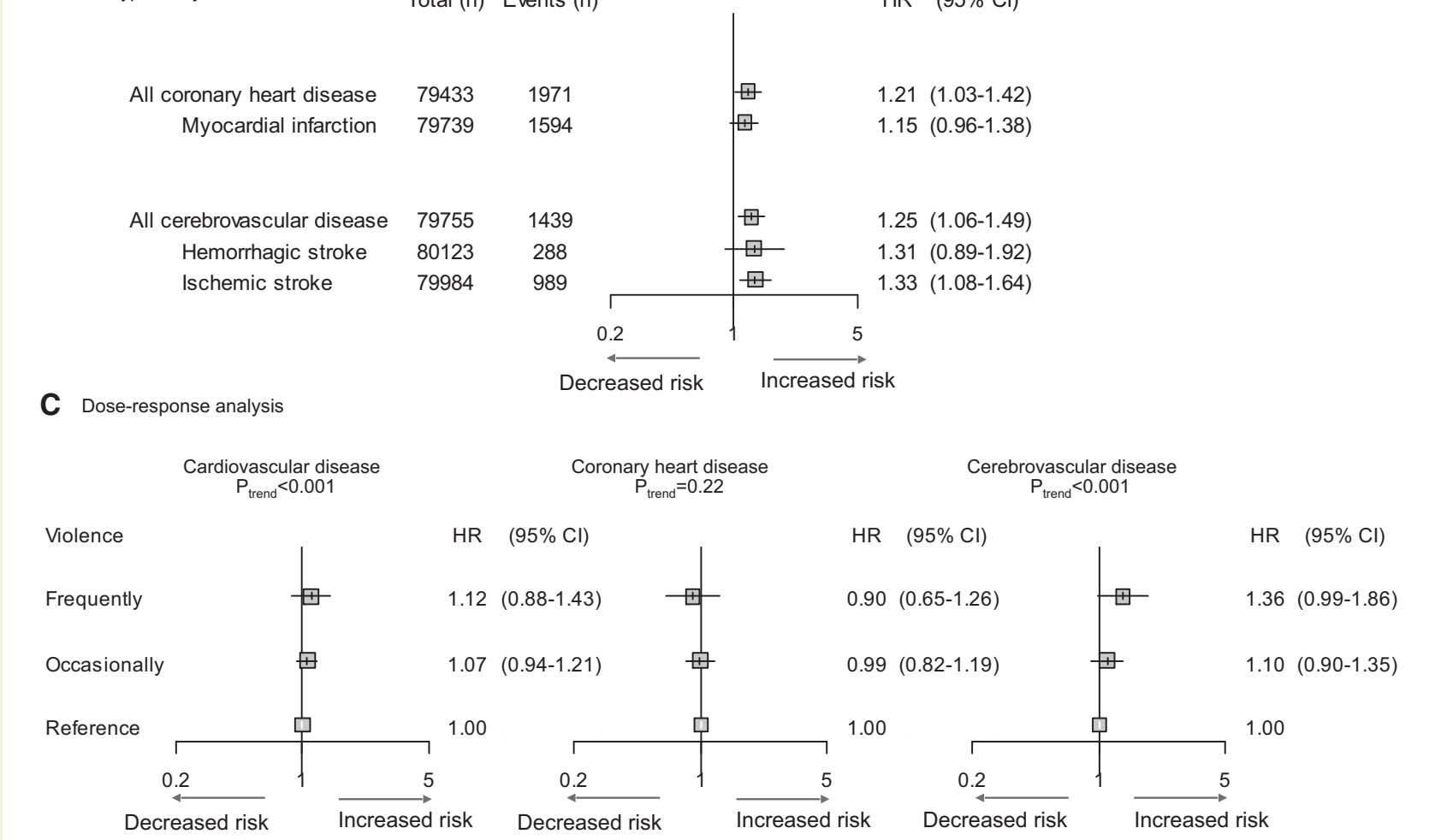

Figure 5 Fixed-effect meta-analysis on the association between workplace violence and cardiovascular disease, after adjustment for age, sex, educational level, marital status, and country of birth, regarding (A) main analysis of cardiovascular disease, (B) subtype analysis of coronary heart disease and cerebrovascular disease, and $(C)$ dose-response relation analysis according to different frequencies of violence.

(12\% of total participant-observations). Treating workplace violence and other changeable statuses, e.g. marital status as time-dependent variables, we found 1.22 times $(95 \% \mathrm{Cl} 0.61-2.44)$ higher risk of having CVD among those exposed to violence, which is consistent with our main analysis from the SLOSH data (HR 1.35, 95\% Cl 0.90-2.02).

\section{Discussion}

In this large multi-cohort analysis involving nearly 80000 employed men and women from Denmark and Sweden, we found consistent support for our hypothesis that workplace bullying and workplace violence are associated with a higher risk of new-onset CVD. The PAR was $5.0 \%$ for workplace bullying and $3.1 \%$ for workplace violence, comparable to those for standard risk factors, e.g. diabetes (4\%) and risky drinking (3-6\%). ${ }^{33,34}$ In this case, if the association was causal, removing workplace bullying and workplace violence from the baseline population prevented $5.0 \%$ and $3.1 \%$ of the CVD cases, respectively. The dose-response relation was evident for both workplace bullying and violence, with the highest risk observed among those exposed on a weekly/daily basis. We observed no heterogeneity between study-specific estimates, and there were no sex differences in the results. The results were robust for different follow-up periods, adjustments, and cardiovascular risk stratifications. 
Follow-up length

Main = full

First 4 years

From 1 year after baseline

Sex

Male

Female

Age

Yonger than 50 years

50 years or older

Current smoking status - in SLOSH and DWECS ${ }^{a}$

Not smoking

Smoking

Adjustments: Mental disorders

Age, sex, educational level, marital status, country of birth

+ Mental disorders

Adjustments: Comorbidity

+ Diabetes

$+\mathrm{CCl}$ score

Adjustments: Life-style factors - in SLOSH and DWECS ${ }^{b}$

Age, sex

Age, sex, educational level, marital status, country of birth

+ Alcohol consumption

+ Smoking

$+\mathrm{BMl}$

+ Alcohol consumption, smoking, BMl

Adjustments: Stressors at private life or workplace

+ Having young children - in SLOSH and DWECS ${ }^{\mathrm{C}}$

+ Family-work conflict - in SLOSH ${ }^{\mathrm{d}}$

+ Role stressors at work - in DWECS ${ }^{e}$

Restriction: Night shift

Only healthcare professionals

Adjustments: Occupational grade

Age, sex, occupational grade, marital status, country of birth

a. Excluding those with missing in smoking status

b. Excluding those with missing in alcohol consumption, smoking and BMI

c. Excluding those with missing information on having young children

d. Excluding those with missing information on family-work conflict

e. Excluding those with missing information on role stressors

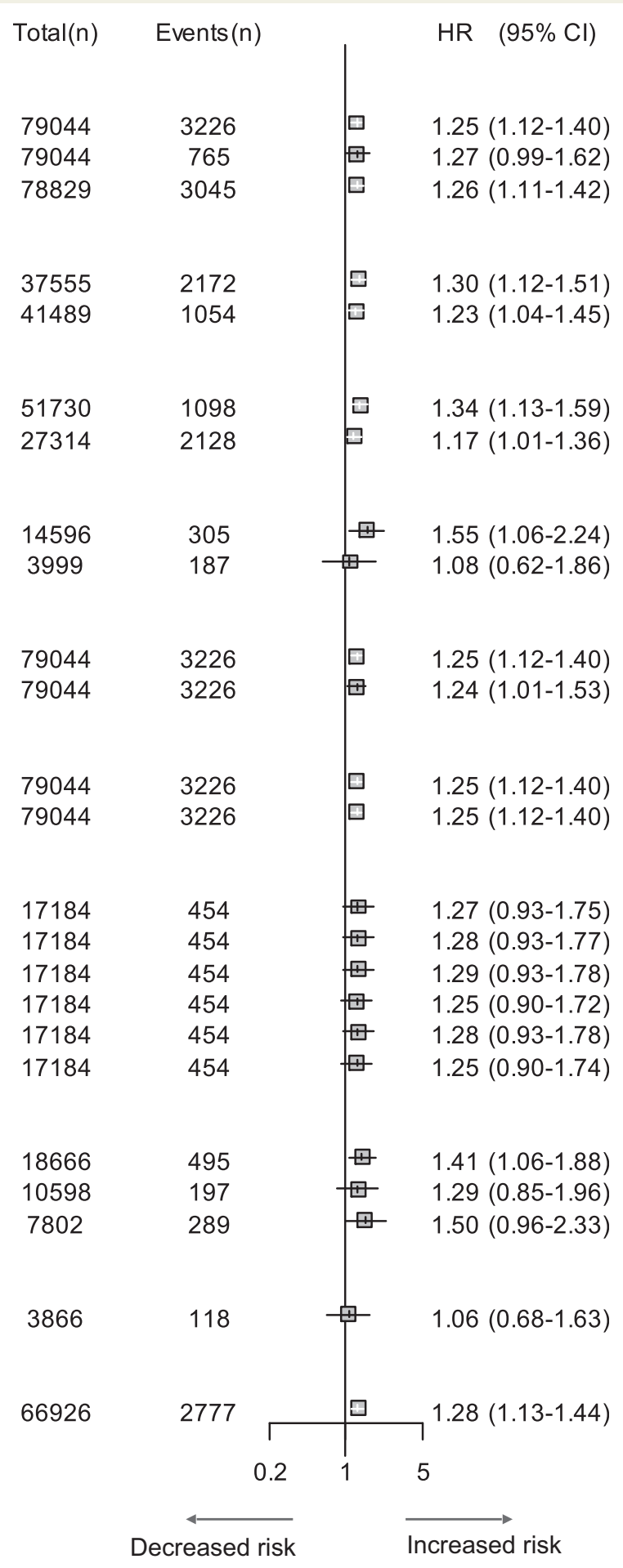

Figure 6 Sensitivity analysis of the association between workplace violence and cardiovascular diseases, using fixed-effect meta-analysis excluding first year(s) of follow-up, stratifying for sex, and with different adjustments and restriction.

\section{Workplace bullying}

Our findings of a higher risk of CVD among those exposed to bullying corroborate with previous studies on the topic. A smaller longitudinal study conducted by Kivimäki et al. ${ }^{15}$ based on a broader selfreported assessment of CVD (hypertension, CHD, and CD) showed that workplace bullying was associated with a 2.3 times higher risk of CVD (95\% Cl 1.2-4.6). After BMI adjustment the risk estimate was similar to the one observed in this study, but no longer statistically significant [odds ratio (OR) 1.6, 95\% Cl 0.8-3.5]. Jacob and Kostev, ${ }^{17}$ using similar CVD definitions as our study, also found similar 


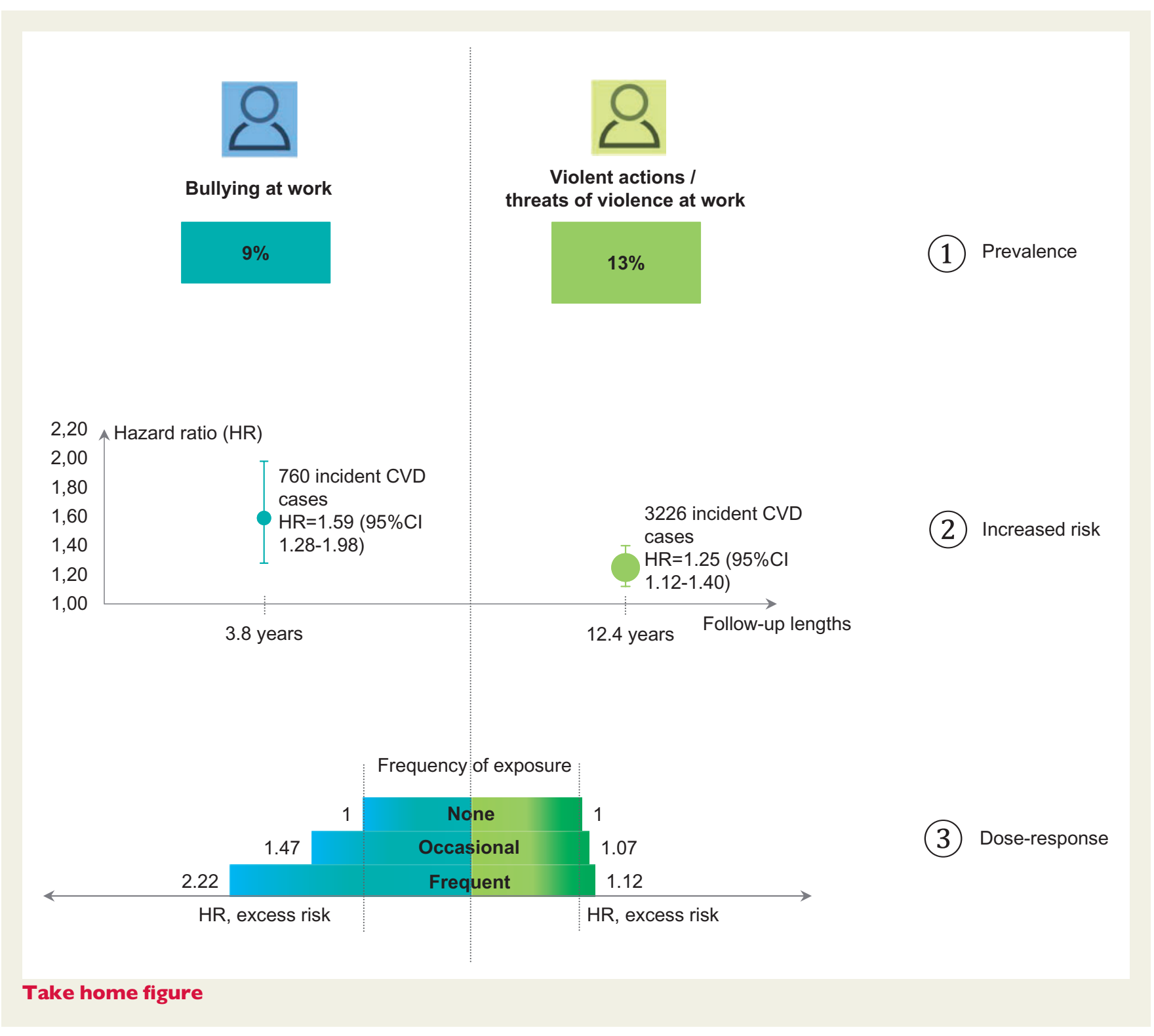

associations (OR 1.31, 95\% Cl 1.01-1.77), and their findings were not affected by further adjustments for overweight.

\section{Workplace violence}

We are not aware of previous studies concerning workplace violence and incident CVD. Our results are in agreement with findings from a recent case-control study from Russia based on 1750 cases and 2000 controls, concerning general violence. They found that physical assault was associated with a 2.14 times higher risk $(95 \% \mathrm{Cl} 1.05-$ 4.34) of ischaemic heart disease death and a 4.36 times higher risk (95\% Cl 1.90-10.00) of CD death. ${ }^{20}$ As our study, to the best of our knowledge, is the first longitudinal investigation of the relation between workplace violence and incident CVD, our findings need to be replicated in other studies. Evidence of a dose-response relation for workplace violence was not as strong as for bullying and only appeared for CD, and not for CHD. It is possible that those most frequently exposed to violence are also those working in frequentclient-contact occupations, as shown in our study. They may be more capable of tackling violence at work with cognitive adaption and their organizations may be also better geared towards preventing long-term consequences of workplace violence. ${ }^{8,28}$ This might be demonstrated by the similar CVD risks observed between frequentand non-frequent-client-contact occupations in our study. Another explanation is that the intensity rather than the frequency of violence is critical in triggering of CHD events. Therefore, more research is needed to clarify the dose-response relation.

\section{Plausible mechanisms}

Workplace bullying and violence are major social stressors. They are likely to induce negative emotions and stress reactions as pathways to CVD development. They may lead to conditions such as anxiety and depression. . $^{810,15,28}$ These negative emotions may also stimulate 
behaviours related to passive coping, such as over-eating and excessive alcohol consumption. ${ }^{5-7}$ Further, activation of the physiological stress response system and activation of the hypothalamic-pituitaryadrenal axis may be involved in direct and indirect mechanisms, e.g. directly causing a higher level of saliva dehydroepiandrosterone and a lower level of saliva cortisol. ${ }^{2}$ These hormones may have a direct impact on heart rate and blood pressure, subsequently leading to hypoperfusion and increased cerebral blood flow pulsatility. ${ }^{1}$ Physiological stress response may be closely related to emotional distress and behavioural changes, ${ }^{11,12}$ indirectly contributing to the elevated level of blood pressure and a greater progressions in intima-media thickness. ${ }^{13,35}$ We did not observe attenuation for both workplace bullying and violence after adjusting for health-related life style factors, but they may still act as mediators. Therefore, further research is needed to investigate these emotional, behavioural, and physiological pathways.

On the other hand, workplace bullying and violence may also have distinct mechanisms. For example, the effect of workplace bullying was markedly affected by follow-up length, while this was not the case for workplace violence. It is plausible that bullying can exacerbate pre-existing CVD risk, such as high atherosclerotic plaque burden. ${ }^{1}$ As those who were bullied at work were very likely to change their job, ${ }^{36}$ this exacerbation might be alleviated after the change. Furthermore, the excess risk associated with bullying was noticeably higher for HS than IS. HS is more strongly associated with high blood pressure than IS. ${ }^{33}$ Accordingly, elevated blood pressure may be more pronounced in the mechanistic pathway between workplace bullying and CVD. ${ }^{16,37}$ However, with the overlapping $\mathrm{Cls}$ of $\mathrm{HS}$ and IS, this latter hypothesis may be a chance finding. Thus, more research is needed to confirm the underlying mechanisms.

\section{Limitations and strengths}

In our study, workplace bullying and violence were measured only once, potentially causing some degree of misclassification of longterm exposure. ${ }^{3}$ However, the supplementary analysis using repeated measures in SLOSH suggests that this is not a major source of bias. Our study was conducted in a Nordic setting, where the concepts of workplace bullying and violence are well-established, ${ }^{38}$ but caution is needed when generalizing the results to other cultural settings, where individuals may perceive workplace bullying and violence differently. Additionally, information on potential confounders such as tobacco use other than smoking (e.g. snus), personality, negative emotional traits, genetic factors, other stressors at private life (e.g. marital conflict), and other work-related stressors were not available in the studies. Further data to evaluate causation and mechanisms for the associations, such as the severity of the exposures and measurements of stress hormones, blood pressure, blood cholesterol, or heart rate variability, were not available to us.

However, importantly, in contrast to previous studies, we were able to link survey data to nationwide registries to identify new cases of definite CVD with nearly complete follow-up. Our large sample size and long follow-up period allowed us to assess the total effects, subtype effects and dose-response relation. It also allowed us to perform relevant sensitivity analyses on different stratifications, adjustments, and restriction with sufficient statistical power.

\section{Conclusion}

Bullying and violence are common workplace stressors. Our study sheds light on their association with a higher risk of cardiovascular events. If the association is causal, eliminating workplace bullying and violence would prevent a sizable number of CVD events from happening. Further research is needed to determine whether preventive measures directed towards bullying and violence may reduce CVD risk as well as to investigate the underlying mechanistic pathways.

\section{Supplementary material}

Supplementary material is available at European Heart Journal online.

\section{Acknowledgements}

The authors thank V. Persson (Stress Research Institute, Stockholm University) for managing the SWES and SLOSH data for analysis.

\section{Funding}

This work was supported by NordForsk, the Nordic Research Program on Health and Welfare (75021), Project on Psychosocial Work Environment and Healthy Ageing and the Danish Working Environment Foundation (09-2016-03). S.S. was funded by Academy of Finland (286294). M.K. was supported by grants from NordForsk, the UK Medical Research Council (K013351), the Academy of Finland (311492), the Finnish Work Environment Foundation and a Helsinki Institute of Life Science (HILIFE) fellowship. M.V. was supported by the Academy of Finland (258598).

\section{Conflict of interest: none declared.}

\section{References}

1. Kivimäki M, Steptoe A. Effects of stress on the development and progression of cardiovascular disease. Nat Rev Cardiol 2018;15:215.

2. Xu T, Magnusson Hanson LL, Lange T, Starkopf L, Westerlund H, Madsen IEH, Rugulies R, Pentti J, Stenholm S, Vahtera J, Hansen ÅM, Kivimäki M, Rod NH. Workplace bullying and violence as risk factors for type 2 diabetes: a multicohort study and meta-analysis. Diabetologia 2018;61:75-83.

3. Einarsen S, Hoel H, Zapf D, Cooper CL, Einarsen S (eds). The concept of bullying and harassment at work: the European tradition. In Bullying and Harassment in the Workplace: Developments in Theory, Research, and Practice. ProQuest Ebook Central: Chapman and Hall/CRC; 2011. p3-40.

4. Krug EG, Mercy JA, Dahlberg LL, Zwi AB. The world report on violence and health. Lancet 2002;360:1083-1088.

5. Torres SJ, Nowson CA. Relationship between stress, eating behavior, and obesity. Nutrition 2007;23:887-894.

6. Rospenda KM, Fujishiro K, Shannon CA, Richman JA. Workplace harassment, stress, and drinking behavior over time: gender differences in a national sample. Addict Behav 2008;33:964-967.

7. McFarlin SK, Fals-Stewart W, Major DA, Justice EM. Alcohol use and workplace aggression: an examination of perpetration and victimization. J Subst Abuse 2001; 13:303-321.

8. Schablon A, Zeh A, Wendeler D, Peters C, Wohlert C, Harling M, Nienhaus A. Frequency and consequences of violence and aggression towards employees in the German healthcare and welfare system: a cross-sectional study. BMJ Open 2012;2:e001420.

9. Menckel E, Viitasara E. Threats and violence in Swedish care and welfaremagnitude of the problem and impact on municipal personnel. Scand J Caring Sci 2002; 16:376-385.

10. Balducci C, Fraccaroli F, Schaufeli WB. Workplace bullying and its relation with work characteristics, personality, and post-traumatic stress symptoms: an integrated model. Anxiety Stress Coping 2011;24:499-513.

11. Burke HM, Davis MC, Otte C, Mohr DC. Depression and cortisol responses to psychological stress: a meta-analysis. Psychoneuroendocrinology 2005;30:846-856.

12. Bazhan N, Zelena D. Food-intake regulation during stress by the hypothalamopituitary-adrenal axis. Brain Res Bull 2013;95:46-53. 
13. Kubzansky LD, Winning A, Kawachi I, Affective states and health. In LF Berkman, I Kawachi, MM Glymour, eds. Social Epidemiology, 2nd ed. New York, NY: Oxford University Press; 2014. p148-168.

14. Theorell T, Jood K, Järvholm LS, Vingård E, Perk J, Östergren PO, Hall C. A systematic review of studies in the contributions of the work environment to ischaemic heart disease development. Eur J Public Health 2016;26:470-477.

15. Kivimaki M, Virtanen M, Vartia M, Elovainio M, Vahtera J, Keltikangas JL. Workplace bullying and the risk of cardiovascular disease and depression. Occup Environ Med 2003;60:779-783.

16. Khubchandani J, Price JH. Workplace harassment and morbidity among US adults: results from the National Health Interview Survey. J Community Health 2015;40:555-563.

17. Jacob L, Kostev K. Conflicts at work are associated with a higher risk of cardiovascular disease. Ger Med Sci 2017;15:Doc08.

18. Suglia SF, Sapra KJ, Koenen KC. Violence and cardiovascular health: a systematic review. Am J Prev Med 2015;48:205-212.

19. Lee EH, Bruckner TA. Threats to security and ischaemic heart disease deaths: the case of homicides in Mexico. Int J Epidemiol 2017;46:173-179.

20. Bhavsar V, Cook S, Saburova L, Leon DA. Physical assault in the previous year and total and cause-specific mortality in russia: a case-control study of men aged 25-54 years. Int J Epidemiol 2017;46:1018-1028.

21. SCB. Arbetsmiljön 2015 [the Working Environment 2015]. https://www.av.se/global assets/filer/statistik/arbetsmiljon-2015/arbetsmiljostatistik-arbetsmiljon-2015-rap port-2016-2.pdf (12 October 2018).

22. Magnusson Hanson LL, Leineweber C, Persson V, Hyde M, Theorell T, Westerlund H. Cohort Profile: The Swedish Longitudinal Occupational Survey of Health (SLOSH). Int J Epidemiol 2018;47:691-692i.

23. Burr H, Bach E, Gram H, Villadsen E. Arbejdsmiljø i Danmark 2005 - et overblik fra den Nationale Arbejdsmiljøkohorte. København: Arbejdsmijøinstituttet, 2006.

24. Ofte stillede spørgsmål. http://www.nvk.dk/forsker/oftest-stillede-spoergsmaal (16 October 2018).

25. Greenland S, Pearl J, Robins JM. Causal diagrams for epidemiologic research. Epidemiology 1999;10:37-48.

26. Piepoli MF, Hoes AW, Agewall S, Albus C, Brotons C, Catapano AL, Cooney MT, Corrà U, Cosyns B, Deaton C, Graham I, Hall MS, Hobbs FDR, Løchen M-L, Löllgen H, Marques-Vidal P, Perk J, Prescott E, Redon J, Richter DJ, Sattar N, Smulders Y, Tiberi M, van der Worp HB, van Dis I, Verschuren WMM. 2016 European Guidelines on cardiovascular disease prevention in clinical practice: The Sixth Joint Task Force of the European Society of Cardiology and Other Societies on Cardiovascular Disease Prevention in Clinical Practice (constituted by representatives of 10 societies and by invited experts)Developed with the special contribution of the European Association for Cardiovascular Prevention \& Rehabilitation (EACPR). Eur Heart J 2016;37:2315-2381.
27. Nielsen MB, Einarsen SV. What we know, what we do not know, and what we should and could have known about workplace bullying: an overview of the literature and agenda for future research. Aggress Violent Behav 2018;42:71-83.

28. Madsen IEH, Burr H, Diderichsen F, Pejtersen JH, Borritz M, Bjorner JB, Rugulies R. Work-related violence and incident use of psychotropics. Am J Epidemiol 2011:174:1354-1362.

29. Madsen IEH, Diderichsen F, Burr H, Rugulies R. Person-related work and incident use of antidepressants: relations and mediating factors from the Danish work environment cohort study. Scand J Work Environ Health 2010;36:435-444.

30. Hernán MA, Robins JM. Causal survival analysis. In Causal Inference. Boca Raton Chapman \& Hall/CRC; 2018 (forthcoming), p69-78.

31. Rockhill B, Newman B, Weinberg C. Use and misuse of population attributable fractions. Am J Public Health 1998;88:15-19.

32. Hedges LV, Vevea JL. Fixed-and random-effects models in meta-analysis. Psychol Methods 1998;3:486

33. O'Donnell MJ, Chin SL, Rangarajan S, Xavier D, Liu L, Zhang H, Rao-Melacini P, Zhang X, Pais P, Agapay S, Lopez-Jaramillo P, Damasceno A, Langhorne P, McQueen MJ, Rosengren A, Dehghan M, Hankey GJ, Dans AL, Elsayed A, Avezum A, Mondo C, Diener H-C, Ryglewicz D, Czlonkowska A, Pogosova N, Weimar C, lqbal R, Diaz R, Yusoff K, Yusufali A, Oguz A, Wang X, Penaherrera E, Lanas F, Ogah OS, Ogunniyi A, Iversen HK, Malaga G, Rumboldt Z, Oveisgharan S, Al Hussain F, Magazi D, Nilanont Y, Ferguson J, Pare G, Yusuf S. Global and regional effects of potentially modifiable risk factors associated with acute stroke in 32 countries (INTERSTROKE): a case-control study. Lancet 2016; 388:761-775.

34. Nilsson P, Nilsson JÅ, Berglund G. Population-attributable risk of coronary heart disease risk factors during long-term follow-up: the Malmö Preventive Project. J Intern Med 2006;260:134-141.

35. Nabi H, Chastang J-F, Lefevre T, Dugravot A, Melchior M, Marmot MG, Shipley MJ, Kivimäki M, Singh-Manoux A. Trajectories of depressive episodes and hypertension over 24 years: the Whitehall II prospective cohort study. Hypertension 2011;57:710-716.

36. Nabe-Nielsen K, Grynderup MB, Conway PM, Clausen T, Bonde JP, Garde AH, Hogh A, Kaerlev L, Török E, Hansen ÅM. The role of psychological stress reactions in the longitudinal relation between workplace bullying and turnover. J Occup Environ Med 2017;59:665-672.

37. Krieger N, Chen JT, Waterman PD, Hartman C, Stoddard AM, Quinn MM Sorensen G, Barbeau EM. The inverse hazard law: blood pressure, sexual harassment, racial discrimination, workplace abuse and occupational exposures in US low-income black, white and Latino workers. Soc Sci Med 2008;67:1970-1981.

38. Nielsen MB, Matthiesen SB, Einarsen S. The impact of methodological moderators on prevalence rates of workplace bullying. A meta-analysis. J Occup Organ Psychol 2010;83:955-979. 